\title{
Intensive BP Control, Falls, and Fractures: Response to Jolobe (MS \#17620)
}

\author{
Karen L. Margolis, M.D., M.P.H. ${ }^{\text {}, ~ G r e g o r y ~ W . ~ E v a n s, ~ M . A . ~}{ }^{2}$, Ann V. Schwartz, Ph.D. ${ }^{3}$, and \\ Jerome Fleg, M.D. ${ }^{4}$
}

'HealthPartners Institute for Education and Research, Minneapolis, MN, USA; ${ }^{2}$ Wake Forest School of Medicine, Winston-Salem, NC, USA; ${ }^{3}$ University of California San Francisco, San Francisco, CA, USA; ${ }^{4}$ National Heart, Lung, and Blood Institute, Bethesda, MD, USA.

J Gen Intern Med 30(5):547

DOI: $10.1007 / \mathrm{s} 11606-015-3191-\mathrm{z}$

(๑) Society of General Internal Medicine 2015

$\mathrm{T}$ o the Editor:

In our study showing no increase in the rate of falls with intensive blood pressure (BP) control in the ACCORD trial, Dr. Jolobe inquires whether the prevalence of orthostatic hypotension differed between the intensive and standard BP control groups. He further notes that orthostatic hypotension may not be accompanied by symptoms. The ACCORD BP trial did gather data on orthostatic BP change and dizziness on standing in a subgroup of participants. Of the 3,099 participants included in our analysis, orthostatic BP measurements and reports of dizziness or lightheadedness on standing during the measurement are available on 905 participants at baseline. We also have data on a subgroup of 607 participants who were assessed for health-related quality of life at baseline and 12 months. This included a question about dizziness on standing within the previous month.

Seated and standing brachial artery BP was measured using an Omron model HEM-907 automatic sphygmomanometer. After 7 min of seated rest, during which BP was measured 3 times, participants were asked to stand. Standing BP was taken every minute for $3 \mathrm{~min}$ in the same arm. BP change was calculated using the lowest of the standing measurements minus the mean of the seated measurements. Orthostatic hypotension was defined as a decline in either systolic BP $\geq 20 \mathrm{mmHg}$ or diastolic $\mathrm{BP} \geq 10 \mathrm{~mm}$.

Orthostatic hypotension was present in $17 \%$ of standard and $21 \%$ of intensive BP group participants at the baseline visit $(p=0.13)$. Dizziness or lightheadedness during these measurements was uncommon and also did not differ between the groups $(5 \%$ of standard and $6 \%$ of intensive BP group participants, $p=0.56$.) Dizziness on standing within the previous month was more common, but did not differ between the
Table 1 Self-reported dizziness on standing within previous month

\begin{tabular}{lllc}
\hline \hline & $\begin{array}{l}\text { Standard } \\
\text { BP Group }\end{array}$ & $\begin{array}{l}\text { Intensive } \\
\text { BP Group }\end{array}$ & $\boldsymbol{p ~ v a l u e ~}^{\mathbf{a}}$ \\
\hline Baseline $(n=585)$ & $28 \%$ & $23 \%$ & 0.18 \\
12 months $(n=589)$ & $25 \%$ & $29 \%$ & 0.36 \\
\hline
\end{tabular}

${ }^{a}$ Testing equality between treatment groups

standard and intensive treatment groups either at baseline or at 12 months of follow-up in the subgroup of participants in these analyses (Table 1). This is similar to the previous report for the ACCORD BP trial. ${ }^{1}$

Our analysis was designed to determine whether intensive BP treatment would affect the risk of falls or fractures, and our findings suggest that intensive treatment is safe with regard to these outcomes. Based on the data presented in this letter, we consider it unlikely that differences in orthostatic hypotension at baseline influenced our results. As Dr. Jolobe notes, an important outstanding question is "whether or not orthostatic hypotension (and its severity) might have contributed to falls in either group." We agree that this is an important question, and we are currently conducting analyses to carefully examine the influence of orthostatic BP change and symptoms on falls and fractures among ACCORD BP trial participants.

Corresponding Author: Karen L. Margolis, M.D., M.P.H.; HealthPartners Institute for Education and Research, Box 1524, Mailstop 23301A, Minneapolis, MN 55440-1524, USA (e-mail: karen.l.margolis@healthpartners.com).

\section{REFERENCE}

1. ACCORD Study Group CW, Evans GW, Byington RP, Goff DC Jr, Grimm RH Jr, Cutler JA, Simons-Morton DG, Basile JN, Corson MA, Probstfield JL, Katz L, Peterson KA, Friedewald WT, Buse JB, Bigger JT, Gerstein HC, Ismail-Beigi F. Effects of intensive blood pressure control in type 2 diabetes mellitus. N Engl J Med. 2010;362(17):1575-85. doi:10.1056/ NEJMoa 1001286. 